\section{(6) OPEN ACCESS}

\title{
Unexplained lymphadenopathies: autoimmune lymphoproliferative syndrome in an adult patient
}

\author{
Fatima Leal-Seabra, ${ }^{1}$ Gonçalo Sarmento Costa, ${ }^{1}$ Henrique Pereira Coelho, ${ }^{2}$ \\ Agripino Oliveira ${ }^{1}$
}

${ }^{1}$ Department of Internal Medicine, Centro Hospitalar Vila Nova de Gaia/Espinho, Vila Nova Gaia, Porto, Portugal ${ }^{2}$ Hematology Service, Centro Hospitalar Vila Nova de Gaia/ Espinho, Vila Nova Gaia, Porto, Portugal

\section{Correspondence to} Dr Agripino Oliveira, agripino@netcabo.pt

Accepted 11 November 2016

\begin{abstract}
SUMMARY
Autoimmune lymphoproliferative syndrome (ALPS) is characterised by massive enlargement of the lymphoid organs, autoimmune cytopenias and a predisposition to develop lymphoid malignancies. The basic defect is a disturbance of the lymphocyte apoptosis, and a high number of circulating TCRab $\mathrm{CD}^{+}{ }^{+} \mathrm{CD} 4^{-} \mathrm{CD} 8^{-} \mathrm{T}$-cells (double-negative T cells (DNT cells)). We describe a case of a 41-year-old man with fever, hepatosplenomegaly, multiple lymphadenopathy, autoimmune haemolytic anaemia and severe thrombocytopenia. Peripheral blood immunophenotyping revealed elevation of the characteristic DNT cells in $8 \%$ and high levels of interleukin 10. Histopathological analysis of lymph nodes showed lymphadenitis with paracortical hyperplasia. It was assumed as a probable diagnosis of ALPS, and the procedure was to medicate the patient with steroids. As a result, a significant clinical improvement was achieved, and he has been in remission for 2 years. To our knowledge, this is the first case reported in a Portuguese adult patient.
\end{abstract}

\section{BACKGROUND}

Autoimmune lymphoproliferative syndrome (ALPS), also known as the Canale-Smith syndrome, is a rare disorder. The increase in DNT cells, interleukin 10 (IL-10) and polyclonal elevation of gamma globulin (IgG) can be diagnostically relevant in patients under suspicion of this syndrome. The genetic defect found in most patients is a mutation in the FAS gene, which encodes a cell surface receptor, on stimulation, and induces a programmed cell death. This entity typically develops in childhood and, in contrast, there are a few reported adult-onset cases. ${ }^{1-3}$

\section{CASE PRESENTATION}

A 41-year-old man, with a history of pulmonary tuberculosis and with no family history of lymphoproliferative and autoimmune diseases, was taken to the emergency department and exhibited multiple cervical, axillary and inguinal lymph node enlargements, and epistaxis with more than a 6-month history. He had had an intermittent fever lasting for 4 months. There was no loss of weight or appetite, neither night sweats nor any other localising symptoms, namely pulmonary symptoms or signs. On physical examination, he had pallor, petechial and oral haemorrhagic bullae.

\section{INVESTIGATIONS}

According to our research on this patient, we found out that he had bicytopaenia with a haemoglobin of $8.7 \mathrm{~g} / \mathrm{dL}$ and platelet count of $4000 / \mu \mathrm{L}$, total leucocyte count was $6650 / \mu \mathrm{L}$ with normal differentials. Liver and renal function tests, prothrombin time and vitamin $\mathrm{B}_{12}$ were all within normal range. Biochemical evidence of haemolysis was supported by serum decresead haptoglobin level, increased indirect bilirubin and lactate dehydrogenase levels. Direct anti-globulin test was positive $\left(\mathrm{IgG3}^{+}\right.$; $\left.\mathrm{C} 3 \mathrm{~d}^{+}\right)$. Abdominal ultrasound revealed a hepatomegaly $(17 \mathrm{~cm})$, splenomegaly $(14,5 \mathrm{~cm})$, as well as retroperitoneal and external iliac adenomegaly about $3 \times 1 \mathrm{~cm}$. Thoracic CT showed axillary adenomegaly of $2 \times 2.5 \mathrm{~cm}$. The infection diagnostic work-up, including blood and urine culture, screening for tuberculosis, HIV, toxoplasmosis, parvovirus, cytomegalovirus, Brucella and hepatitis, was all negative. The autoimmune work-up was also negative. The patient's bone marrow biopsy was normal. In addition, ganglion excisional biopsy excluded malignancy and mycobacteriology cultures were negative for Mycobacterium tuberculosis or other nontuberculous Mycobacterium. Flow cytometry of peripheral blood reported that $8 \%$ of the lymphocytes were DNT cells. Plasma concentrations of soluble interleukin-10 (IL-10) were increased, but none FAS and FASL mutations was detected (tables 1 and 2). A probable ALPS diagnosis was made.

\section{TREATMENT}

In the acute phase, $1 \mathrm{mg} / \mathrm{kg}$ of IgG was first administered and $10 \mathrm{mg} / \mathrm{kg}$ methylprednisolone over 3 days, followed by maintenance dose of $1.5 \mathrm{mg} / \mathrm{kg}$ per day prednisolone. He began to show a response after 2 weeks and the platelet count was normal in just 1 month. A complete remission of the clinical and laboratory abnormalities was achieved after a prolonged prednisolone tapering over the period of 12 months.

\section{OUTCOME AND FOLLOW-UP}

We have been closely following him up every month, and his lymphadenopathy and hepatosplenomegaly have regressed (ultrasound liver $15.7 \mathrm{~cm}$ and spleen $10.8 \mathrm{~cm}$ ). The axillary nodes have disappeared, and the cervical nodes have been just palpable for 2 months. After a 24-month follow-up without any treatment, the patient is asymptomatic and with no evidence of recurrence. It was programmed a lymphocyte apoptosis assay and a positron emission tomography (PET) scans to keep the patient under surveillance. 
Table 1 Results of laboratory tests released to patient during the study

\begin{tabular}{|c|c|c|}
\hline & Patient values & $\begin{array}{l}\text { Reference } \\
\text { values }\end{array}$ \\
\hline Total bilirubin & $2.07 \mathrm{mg} / \mathrm{dL}$ & $0.1-1.1$ \\
\hline Directed bilirubin & $0.69 \mathrm{mg} / \mathrm{dL}$ & $0.1-0.3$ \\
\hline Lactate dehydrogenase & $618 \mathrm{U} / \mathrm{L}$ & $135-225$ \\
\hline Haptoglobin & $<10.0 \mathrm{ng} / \mathrm{mL}$ & $30-200$ \\
\hline Direct antiglobulin test & $\operatorname{lgG} 3+;$ C $3 d 1+$ & \\
\hline Aspartate aminotransferase & $44 \mathrm{U} / \mathrm{L}$ & $4-33$ \\
\hline Alanine aminotransferase & $50 \mathrm{U} / \mathrm{L}$ & $4-50$ \\
\hline$\gamma$-glutamyl transferase & $71 \mathrm{U} / \mathrm{L}$ & $5-61$ \\
\hline $\mathrm{C}$ reactive protein & $3.79 \mathrm{mg} / \mathrm{dL}$ & $0-0.5$ \\
\hline $\begin{array}{l}\text { Polyclonal } \\
\text { hypergammaglobulinaemia }\end{array}$ & $2710 \mathrm{mg} / \mathrm{dL}$ & \\
\hline Activated partial thromboplastin time & $42.4 \mathrm{~s}$ & $28.0-40.0$ \\
\hline Peripheral blood assays & $\begin{array}{l}\text { IL-10: } 22.8 \mathrm{pg} / \mathrm{mL} \\
\text { FASL: } 143 \mathrm{pg} / \mathrm{mL}\end{array}$ & $\begin{array}{l}\leq 20 \\
\leq 200\end{array}$ \\
\hline $\begin{array}{l}\text { Immunophenotyping of peripheral } \\
\text { blood lymphocytes }\end{array}$ & $8 \%$ TCRab CD3 ${ }^{+}$CD4 & CD8- T-cells \\
\hline
\end{tabular}

\section{DISCUSSION}

ALPS is a disease characterised by immune dysregulation due to an inability to regulate lymphocyte homoeostasis through abnormalities in lymphocyte apoptosis or programmed cell death. The required clinical criteria are the presence of chronic lymphadenopathy and splenomegaly, present for more than 6 months, which may be asymptomatic and incidentally identified during routine physical examinations. In our case, the patient presented with hepatomegaly, splenomegaly and multiple lymph node enlargements during a period of 6 months. Patients with ALPS may present initially with episodes of fatigue, pallor and icterus due to haemolytic anaemia. They may also be more likely to have easy bruising and mucocutaneous bleeding caused by thrombocytopenia. In our case, the patient was taken to the emergency room with pallor, petechial, oral haemorrhagic bullae and a platelet count of $4000 / \mu \mathrm{L}$.

Patients with ALPS can also have multilineage cytopenias, more typically in adults, ${ }^{45}$ which are chronic and can be refractory to therapy. The autoimmune haemolytic anaemia is also a common manifestation while immune neutropenia is rare. ${ }^{4}$ In

Table 2 Results of histopathological and genetics analysis released during the study

Bone marrow biopsy Anatomopathological examination: 3 haematopoietic lines were observed. The erythroid line was increased with normoblasts and megakaryocytic line with many dysmorphic elements. No changes to granulocytic line. Without malignancy characteristics.

Immunophenotyping: without changes.

Axillary lymph node Anatomopathological examination: preservation of excisional biopsy lymph node architecture and reactive character changes without malignancy characteristics; Acid-alcohol resistant bacillus: negative; Mycobacteriology cultures: negative; Immunophenotyping: without changes.

Fas gene detection Mutations not detected, but the method used does not exclude mutations outside the FAS gene regions analysed or not detectable by sequencing. Unrealised searching for deletions or duplications in the FAS gene and sequencing of FASL or CASP10 genes. this case, patient showed a haptoglobin decrease, an indirect bilirubin and a lactate dehydrogenase increased and a positive direct antiglobulin test $\left(\operatorname{IgG~} 3^{+}\right.$; $\left.\mathrm{C} 3 \mathrm{~d}^{+}\right)$, compatible with autoimmune haemolytic anaemia. The incidence of lymphomas is quite significant. Therefore, a bone marrow aspiration was performed which showed no suggestive lymphoproliferative disorders of marrow involvement. In ALPS diagnosis, the peripheral blood immune phenotyping is essential to find the DNT cells elevation. ${ }^{5}{ }^{6}$ Moreover, regarding our patient, it was observed a flow cytometry which showed $8 \%$ of the lymphocytes total to be DNT cells, one the required criterion (to have more than $1.5 \%$ in the setting of normal lymphocyte counts). When this condition is suspected, mutation molecular genetic test of FAS, FASL and CASP10 genes are necessary, because they have diagnostic and prognostic value, as there is an increased risk of lymphoma development. ${ }^{4}$ The pathogenesis of ALPS in the majority of patients result in defective apoptosis of lymphocytes (table 2) mediated through the FAS/FAS ligand (FASL) pathway or mutations in CASP10. In cases where no mutation was identified, a functional deficiency of FAS-mediated apoptosis was also observed. $^{145}$ In our case, we did not search into two separate assays the lymphocyte apoptosis or searched deletions or duplications in the FAS gene and sequencing of FASL or CASP10 genes, as required in the ALPS additional primary criteria (box 1). However, it is no longer considered essential for the diagnosis of ALPS, as patients with somatic or germline FAS mutations, FASL mutations can present with normal in vitro FAS-induced apoptosis assays. ${ }^{5}$ These findings led the authors in the National Institutes of Health Clinical Center Group to propose a classification scheme based on the several different molecular abnormalities. Patients who fulfil ALPS diagnostic criteria and have germline homozygous or heterozygous mutations in FAS, should be named as ALPS-FAS; if they have somatic FAS mutations as ALPS-SFAS; if they have FAS ligand mutations as ALPS-FASL or if they have caspase-10 mutations, they should be classified as ALPS-CASP10. However, when patients have an indeterminate genetic defect, like in your patient's case, they are categorised as ALPS-U (undetermined). ${ }^{4}$

Some biomarkers, which are increased in ALPS, include soluble FASL, circulating IL-10 and vitamin $\mathrm{B}_{12}$, whose biological origin is unknown. ${ }^{5}$ The combinations of these markers can be highly likely to diagnose ALPS instead of FAS sequencing. The new consensus ALPS classification and the inclusion of these biomarkers in diagnostic criteria will expedite ALPS diagnosis. $^{14}$

According to reviewed ALPS criteria, the lymphocyte apoptosis defects detection and somatic or germline mutation identification (FAS, FASL, or CASP10 genes) are primary additional criteria (box 1). Whereas an elevation of biomarkers, anatomopathological findings, autoimmune cytopenias with an elevated IgG levels and family history disease are considered as secondary additional ALPS diagnostic criteria (box 1). In our patient's case, no autoimmunity or lymphadenopathy has occurred in his family background. Also, we observed haemolytic anaemia with polyclonal hypergammaglobulinaemia and an increased IL-10.

Although some patients do not need treatment, most of them require immunosuppressive therapy, mainly those who develop cytopenias. ${ }^{14}$ The treatment is based on high doses of glucocorticoids and G-immunoglobulin intravenous associated ${ }^{4}$ with a good response. ${ }^{5}$ The glucocorticoids should be used only in exacerbations, but discouraged as chronic therapeutic due to its association with many side effects and complications. ${ }^{5}{ }^{6}$ In exacerbation disease, the methylprednisolone pulses $(5-10 \mathrm{mg} / \mathrm{kg})$ must be used for 7-10 days, the prednisolone maintenance therapy $(1-2 \mathrm{mg} / \mathrm{kg})$ 
Box 1 Autoimmune lymphoproliferative syndrome

(ALPS) diagnostic criteria based on the first international workshop of ALPS $2009^{5}$

\section{Required criteria}

1. Chronic (>6 months), non-malignant, non-infectious lymphadenopathy and/or splenomegaly

2. Elevated $\mathrm{CD}^{+}{ }^{+} \mathrm{TCR} \alpha \beta^{+} \mathrm{CD}^{-}{ }^{-} \mathrm{CD} 8^{-}$DNT cells $(>1.5 \%$ of total lymphocytes or $>2.5 \%$ of $\mathrm{CD}^{+}$lymphocytes) in the setting of normal or elevated lymphocyte counts

Additional criteria

1. Primary

1. Defective lymphocyte apoptosis in two separate assays

2. Somatic or germline pathogenic mutation in Fas, FASL or Casp10

2. Secondary

1. Elevated plasma sFASL levels $(>200 \mathrm{pg} / \mathrm{mL})$, plasma interleukin 10 (IL-10) levels (>20 pg/mL), serum or plasma vitamin $\mathrm{B}_{12}$ levels (>1500 $\mathrm{ng} / \mathrm{L}$ ) or plasma IL-18 levels $>500 \mathrm{pg} / \mathrm{mL}$

2. Typical immunohistological findings as reviewed by a haematopathologist

3. Autoimmune cytopenias (haemolytic anaemia, thrombocytopenia or neutropenia) with elevated IgG levels (polyclonal hypergammaglobulinaemia)

4. Family history of a non-malignant/non-infectious lymphoproliferation with or without autoimmunity Definitive diagnosis: Both required criteria plus one primary accessory criterion.

Probable diagnosis: Both required criteria plus one secondary accessory criterion.

for 1 week, followed by a decreased dose to discontinuation over 8 to 12 weeks. $^{6}$ In the case of severe and refractory cytopenias, patients may need intensive care due to hypoxia, and the use of $30 \mathrm{mg} / \mathrm{kg}$ methylprednisolone pulses. ${ }^{6}$ The $\mathrm{G}$ immunoglobulin (1$2 \mathrm{~g} / \mathrm{kg}$ ) should be administered concomitantly with methylprednisolone to avoid an increment of erythrocyte destruction in autoimmune haemolytic anaemia. ${ }^{5}$ In the acute phase, our patient needed $1 \mathrm{mg} / \mathrm{kg}$ of G-immunoglobulin and $10 \mathrm{mg} / \mathrm{kg}$ methylprednisolone for 3 days and after $1.5 \mathrm{mg} / \mathrm{kg}$ per day of prednisolone. The mycophenolate mofetil and sirolimus are becoming an alternative in infancy refractory cytopenias. ${ }^{46}$

Some patients with thrombocytopenia and ALPS do not have a response to $\mathrm{G}$ immunoglobulin; in selected cases of non-controlled hypersplenism and medical treatment failure, ${ }^{4}$ patients can be treated by splenectomy and rituximab $\left(375 \mathrm{mg} / \mathrm{m}^{2}\right.$ per week for four doses), respectively. ${ }^{4}$ The experience with other immunosuppressants in the ALPS is very limited. ${ }^{4}$ The haematopoietic stem cell transplantation is the unique potential curative therapy, which is reserved for the highly refractory disease. ${ }^{4}$ Novel and non-toxic targeted lymphocytic therapies may become available in the future, but it is mandatory to search for new genetic mutations in the subgroup of patients with ALPS with unknown genetic defects. ${ }^{4}{ }^{6}$ In this clinical case, we assumed probable ALPS due to the presence of both required and three secondary accessory criteria. Additionally, after the beginning of immunosuppressive therapy with steroids, the patient had a dramatic clinical improvement. The patient remained in remission after a 24-month corticosteroids treatment.

In fact, the hallmark of this case is the diagnosis made in adulthood. The ALPS is usually diagnosed in childhood, presenting at an average age of 2.5 years, whereas adult cases have rarely been reported. ${ }^{3}$ On the other hand, follow-up studies in individuals who share genetic apoptosis defects revealed that clinical expression of ALPS might be highly variable. ${ }^{2}$ The penetrance of the disease seems to be indirectly related to the site of the mutations. Thus, the diagnosis may be delayed, usually until the development of the first signs of the autoimmune disease. The occurrence of immune cytopenias associated with lymphoproliferation in adulthood should also prompt the physician to consider a diagnosis of ALPS. We classified this case as ALPS-U as there was no detection of a genetic defect. However, mutations outside of the regions analysed as FAS gene deletions or duplications neither FASL, nor CASP10 genes were not excluded. At this point, we know that the patients with mutations in the FAS protein are at risk of developing lymphomas, so they require a lifelong follow-up. ${ }^{5}$

\section{Learning points}

- Autoimmune lymphoproliferative syndrome (ALPS) is an uncommon disease in adult patients, and this disorder is associated with abnormalities in lymphocyte apoptosis and a high number of circulating TCRab $\mathrm{CD}^{+} \mathrm{CD} 4^{-} \mathrm{CD} 8^{-}$T-cells (DNT cells).

- Patients do not need treatment, but when they develop cytopenias, they require immunosuppressive therapy. This is based on high doses of glucocorticoids and IgG intravenous, and the experience with other immunosuppressants in ALPS is very limited.

- Genotyping of the genes associated with ALPS are no longer considered essential for the diagnosis but it can be helpful in patients with confusing clinical and/or laboratory findings and in prognosis definition.

- The incidence of lymphomas is quite significant and therefore a permanent follow-up is needed.

Contributors All authors had been involved in this patient's care. FLS and GSC contributed to the drafting of the manuscript. HPC contributed to the interpretation of data $\mathrm{AO}$ revised the content and accepts responsibility for the overall content as a guarantor.

Competing interests None declared.

Patient consent Obtained.

Provenance and peer review Not commissioned; externally peer reviewed.

Open Access This is an Open Access article distributed in accordance with the Creative Commons Attribution Non Commercial (CC BY-NC 4.0) license, which permits others to distribute, remix, adapt, build upon this work non-commercially, and license their derivative works on different terms, provided the original work is properly cited and the use is non-commercial. See: http://creativecommons.org/ licenses/by-nc/4.0/

\section{REFERENCES}

1 Neven B, Magerus-Chatinet A, Florkin B, et al. A survey of 90 patients with autoimmune lymphoproliferative syndrome related to TNFRSF6 mutation. Blood 2011;118:4798-807

2 Deutsch M, Tsopanou E, Dourakis SP. The autoimmune lymphoproliferative syndrome (Canale-Smith) in adulthood. Clin Rheumatol 2004;23:43-4.

3 Lambotte 0 , Neven B, Galicier L, et al. Diagnosis of autoimmune lymphoproliferative syndrome caused by FAS deficiency in adults. Haematologica 2013;98:389-92.

4 Li P, Huang P, Yang Y, et al. updated understanding of autoimmune lymphoproliferative syndrome (ALPS). Clin Rev Allergy Immunol 2016;50:55-63.

5 Rao VK, Oliveira JB. How I treat autoimmune lymphoproliferative syndrome. Blood 2011;118:5741-51.

6 Rao VK. Approaches to managing cytopenias in autoimmune lymphoproliferative syndrome (ALPS). Front Pediatr 2015;3:65. 
Copyright 2016 BMJ Publishing Group. All rights reserved. For permission to reuse any of this content visit http://group.bmj.com/group/rights-licensing/permissions.

BMJ Case Report Fellows may re-use this article for personal use and teaching without any further permission.

Become a Fellow of BMJ Case Reports today and you can:

- Submit as many cases as you like

- Enjoy fast sympathetic peer review and rapid publication of accepted articles

- Access all the published articles

- Re-use any of the published material for personal use and teaching without further permission

For information on Institutional Fellowships contact consortiasales@bmjgroup.com

Visit casereports.bmj.com for more articles like this and to become a Fellow 